\title{
Problems of water supply of the population and application of the method of electrolysis- structural activation for partial solution
}

\author{
Ludmila Prikhodko ${ }^{1, *}$, Galina Bryukhanova ${ }^{1}$ and Ekaterina Beljakova ${ }^{1}$ \\ ${ }^{1}$ Sochi State University, Sovetskaya street, 26A, 354000, Sochi, Russia
}

\begin{abstract}
We analyzed the problems of water supply for the population of global scale and regional importance. A method for the electrolysisstructural activation of water oriented on the use of initial fresh rainwater or desalinated membrane technology of sea water in a mix with biologically purified household sewage waters. This method can be used on sea vessels, in arid regions of the planet, and in areas with saline groundwater. Activation of water is achieved by mixing biologically purified wastewater obtained by technology that ensures the quality of purified water at the level of requirements for release in a fishery pond and desalinated water (rainwater) or obtained by reverse osmosis in a ratio of their volumes not more than 10:1
\end{abstract}

\section{Introduction}

Today, mankind has faced the most serious challenges and threats to the environmental safety of the environment during the entire historical period of its existence, among which the key is the violation of water balance on the planet. In accordance with the National Security strategy of the Russian Federation up to 2020, the strategic objectives of environmental safety and rational nature management are: to preserve the natural environment, to ensure its protection and elimination of environmental consequences of economic activity in conditions of increasing economic activity and global changes of climate [1]. The problem of the transformation of the natural environment under the influence of natural and anthropogenic factors began to manifest itself more clearly from the second half of the twentieth century, which led to a deterioration in the habitat of not only natural communities, but also man himself. In connection with these processes, the questions of the sustainability of the economic development of the vast territories of the planet and individual countries, the prospects for the existence of modern civilization are becoming more acute and require quite definite actions. The need to reduce the negative impact of global and regional processes of different genesis on the planet as a whole and its individual environments, territories, the importance of preserving biological diversity for subsequent generations have led to the need to develop sound solutions for the sustainable development of states and their territories.

*Corresponding author: miladon1@rambler.ru 


\section{Object of study}

With the development of civilization and the expansion of the technical capabilities of the hydrosphere in many countries of the world, and in recent years in the Russian Federation, it is becoming more intensive, the territory of the Southern Federal District is no exception. This process includes the development of small reservoirs and the exploitation of ever larger ones; increasing the exploitation of available biological resources; the implementation of measures that increase the efficiency of reproduction of biological resources, the transformation of water bodies and cultivated lands, which are subject to the principles used in agricultural production [2].

The largest forms of aquaculture include melioration of natural reservoirs, which allows fuller use of the possibilities of natural aqua systems. The South of Russia is characterized by intensive management of water bodies and their design in order to optimize the production of bioresources in reservoirs.

The development of the hydrosphere in the SFD is carried out in three directions, between which it is sometimes difficult to draw a clear line: firstly, irrigation farming is widely used; secondly, the maximum use of natural and artificial reservoirs as economic commercial lands is carried out in order to obtain the maximum production of fish resources (limnoculture); Thirdly, water use technologies are widely used to grow such an agricultural crop as rice (forming rice checks).

Thus, due to the acclimatization of commercial herbivorous fish, the fish productivity of the small reservoirs of the Caucasus increased to 2-4 centners per hectare. It is considered promising and fish farming in rice fields is applied in a number of places [2].

The problem of clean water and protection of water ecosystems is becoming more acute as the industrial development of society. Already in a number of subjects of the Southern Federal District there are great difficulties in providing water consumption (drinking and technical water supply, irrigation, etc.) and water use (recreation, navigation, energy) due to the quantitative and qualitative depletion of water resources, which is associated with the pollution of water bodies due to high anthropogenic load in one of the most densely populated regions of Russia. At the same time, pollution of water reservoirs increases every year and with simultaneous increase in water consumption in the interests of industrial and agricultural development of the subjects of the Southern Federal District.

In recent years, SFD entities have noted irregularities in the management of production and consumption wastes, the main ones being unauthorized warehousing of waste, their import and export without licenses, incineration of waste, their excessive accumulation and rejection of measures for neutralization of generating waste. Among violations of water legislation, discharges of untreated waste water into reservoirs, lack of treatment facilities, irrational use of water resources, inadequate operation of local treatment facilities, violation of the regime of use of water protection zones are more often recorded.

Infringements of the land legislation are mainly caused by the discharge of combustible and lubricating materials to unprotected soil, soil contamination during manure removal from livestock complexes, pollution of lands by untreated wastewater, chemical contamination of lands, lack of protective measures, leading to deterioration of the soil-plant layer.

Thus, in the subjects of the South Federal District, as in the whole country and in the world, the problems of rational land and water use, provision of the population with goodquality drinking water, nutritionally balanced protein and vitamin-mineral nutrition, and utilization of household and industrial waste are toFigal. At the same time, anthropogenic influence in the densely populated southern region of the country introduces significant changes in the natural processes of the water cycle occurring in the atmosphere, seas, inland water bodies and underground aquifers, influencing the hydrological cycle in vast plains and mountains. According to Kovaleva EP with et al. [3], such a person's activity acquires the 
scale of geological processes.

The main problems in the use of surface water resources in the Krasnodar region can be considered: the problems of interregional regulation and redistribution of flow between water user groups; problems associated with the operation of the Krasnodar Reservoir; problems of water availability of irrigated lands, especially rice reclamation complex; problems of water disposal and ecological condition of irrigated and adjoining lands; problems of water availability of industrial enterprises and especially electric power industry; problems of fishery water use and water use in housing and communal services. The scale and significance of these issues are different, but all of them require their solution [4]. In connection with the reduction of industrial and agricultural production, water consumption in the Krasnodar region has decreased by $30 \%$ since 1990 , the trend has changed in 2000-2008, when the growth of water consumption and water use, associated with the growth of industrial and agricultural sectors of the economy and a sharp seasonal increase in the recreational use of citizens who came to the south for beach recreation. According to the administration of the Krasnodar region, by 2015 the number of holidaymakers on the coast will increase to 20 million people. Prospects for socio-economic development of the region and the expected modernization of the main sectors of the economy - industry, agro-industrial complex, housing and communal services and sanatorium complex, imply an increase in the demand for water resources, taking into account the rationalization of water use and the reduction of the specific water consumption.

According to the Ministry of Natural Resources of the Krasnodar region [5], in 2016, 3442.91 million $\mathrm{m} 3$ of collector-drainage and waste water were discharged into the natural surface water bodies of the Krasnodar region (in 2015 - 2,976.14 million m3), in including normatively clean (without cleaning) 2421.34 million m3 (in 2015 - 2009.80 million m3). Out of 1,021.57 million $\mathrm{m} 3$ of polluted and waste-water-contaminated wastes (in 2015 966.34 million $\mathrm{m} 3$ ), 738.34 million $\mathrm{m} 3$ were dumped into the natural surface water bodies of the region: in 2015, 699, 05 million $\mathrm{m} 3$ ), 162.54 million $\mathrm{m} 3$ (162.54 million $\mathrm{m} 3$ ) in 2015 (158.72 million $\mathrm{m} 3$ in 2015), 120.69 million $\mathrm{m} 3$ of normatively treated wastewater treatment facilities (in 2015 - 108, 57 million $\mathrm{m} 3$ ). The share of discharged untreated wastewater remains high, although the volume of normatively purified water remains very modest (Figture 1).

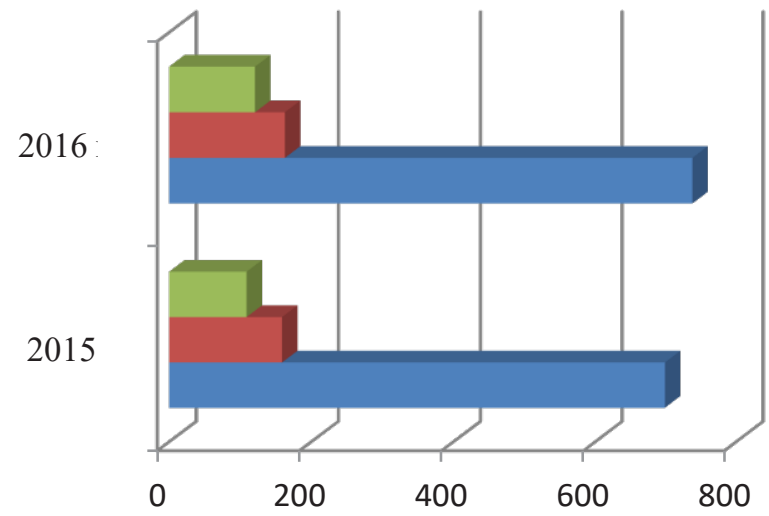

normally purified

- insufficiently purified

without cleaning

Fig. 1. Growth of volumes contaminated and requiring wastewater treatment in the Krasnodar region in 2016 as compared to 2015.

According to the data of the State Budgetary Healthcare Institution of the Medical Information and Analytical Center [5], in 2015, in the structure of diseases, both among the 
general population, and among children aged 0 to 14 and adolescents $15-17$ and adults over 18 The first place was occupied by diseases of the respiratory system, the second - injuries, poisoning and some other consequences of external causes. Among the total population the third place was occupied by diseases of the digestive system, the fourth - diseases of the genitourinary system, the fifth place - diseases of the circulatory system, it is known that diseases occupying from 3 rd to 5 th rank places belong to pathologies with a high ecological component in the etiology, and the main pathway of ecotoxicants in the human body - water and food. This affects the overall and primary morbidity of the entire population, the adolescent and adult population, which tend to increase (Figture 2), a slight decrease in the incidence is noted in the group of the children's population, in which there is a clear upward trend in the proportion of patients with diabetes mellitus.

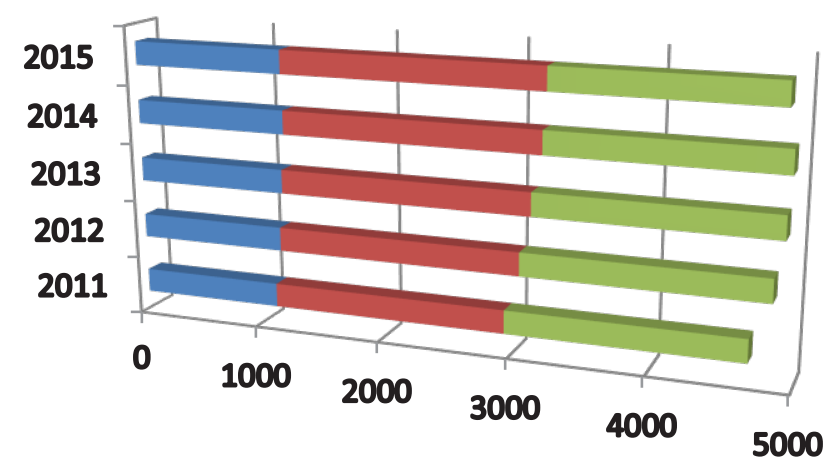

Fig. 2. Dynamics of general population morbidity of Krasnodar region.

According to the monitoring data [5] in 2011-2016, the priority substances polluting the potable water of the centralized drinking-water supply systems of the Krasnodar region are: calcium and magnesium salts, iron, manganese and its compounds, ammonia, nitrates, sulfates, sulfides and hydrogen sulphide, fluorides, chlorides. The greatest percentage of samples that did not meet the sanitary and epidemiological requirements for the content of chemical pollutants was noted in 2016 in Primorsko-Akhtarskiy, Timashevsky, Bryukhovetskiy, Kanevsky, Krylovsky, Yeisk, Leningradsky districts, Anapa, Kushchevsky, Slavyansky, Gulkevichsky, Novokubansky, Seversky, Abinsk districts.

The economic block of requirements for the concept of sustainable development provides for optimal use of limited resources; development and application of environmentally friendly environmental, energy and resource-saving technologies, including extraction and processing of raw materials; introduction of waste-free processes for obtaining the product; creation of environmentally friendly products; improvement of technologies for processing and destruction of production and consumption wastes.

Thus, the current state and the development of a strategy for the harmonious development of a particular territory can not be considered in isolation from the hierarchy of its position in the system of coordinates of the preservation of water bodies, regulation of water balance and the introduction of technologies for wastewater treatment. Proceeding from this, we proposed the use of the method of electrochemical oxidation of an aqueous "cocktail" (of a mixed composition: with initially different concentrations of salts - rainwater or sea - with wastewater subjected to deep biological purification) in order to bring it to the normative quality with the possibility of drinking in drinking purposes. The use of rain or sea water as a component of a "cocktail" is determined by their initially high acidity. Acid rainfall in developed countries has already caused the erosion of a number of world cultural heritage sites, a decrease in the volume of fisheries in lakes, as well as defoliation and degradation of the forest fund. 
The method for obtaining slightly alkaline water is oriented to the use of initial weakly acid (or different degrees of acidity) of rainwater, or desalinated membrane technology of sea water in a mixture with biologically purified domestic wastewater and can be used in installations on anthropogenically contaminated ecologically depressant water areas, as well as on sea vessels, on arid territories of the planet, in space ships and in regions of the world with saline groundwater.

The method involves the preliminary collection of rainwater or salt water desalted by membrane technology (step 1). Step 2: selection of domestic sewage after their deep biological treatment. Stage 3: mixing of natural (rainwater, desalinated) and waste water after its deep biological purification (in proportion not more than 10:1). Step 4: Carry out the electrolysis of such a "cocktail" (electrochemical activation) in order to obtain slightly alkaline water with a) the subsequent completion of its composition according to hygienic standards to a quality that meets the requirements for the production of aquaculture in fishery water bodies, and its use for this purpose, b) the use of slightly alkaline water for domestic purposes for guaranteed water supply to the population of the residential area.

The phenomenon of the formation of alkalescent water in the mountains is known in the melting of glaciers and the flow of water currents in river beds, when it is in contact with various rocks. [6]. People living along the banks of such rivers and streams are long-livers. But, unfortunately, the use of water of this quality for all the inhabitants of the planet is impossible.

Closer to this quality are the ways of obtaining drinking water by evaporating the sea and collecting condensate, or by passing salt water through reverse osmosis membranes, and then enriching the distillate with a set of salts necessary for the normal functioning of the human body. These methods are applicable in conditions of long transitions of swimming means in the oceans, as well as when living in arid coastal areas [7].

The introduction of a complex of necessary anions and cations in the above-mentioned methods for the production of potable water is a complex operation requiring careful preparation. The proposed method for obtaining weakly alkaline water differs in that it assumes a partial replenishment of the mineral composition in the final product by mixing biologically purified wastewater and desalinated water (rainwater) or obtained by reverse osmosis in a ratio of their volumes of not more than 10: 1. Sewage water is purified by technology that provides water quality at the level of requirements for release into a fishery reservoir for particularly valuable fish species. In the reservoir, microalgae such as chlorella or stsenodemus are cultivated to bring the quality of water to the drinking normative [8].

Wastewater from an air, sea vessel, spacecraft, as well as populated areas, water from surface and (or) underground highly mineralized reservoirs can be used as part of a "cocktail" for obtaining water of guaranteed quality, suitable for re-use for domestic purposes.

On average, a person living in sparsely populated areas needs 100-250 liters / person to dispatch household needs. day, the average volume of water consumption for residents of major cities in the world reaches 350 or more litre for person per day. During the biological treatment of wastewater, as well as the preliminary mechanical cleaning of waste water, along with the refuse from the grids, sand from the sand, precipitation released in the sedimentation tanks, which have undergone thickening, dehydration, and as a result of evaporation in the bioreactors, part of the water is completely lost (at least $10 \%$ of the volume of effluent that has flowed to the treatment plant), and these losses must be compensated by bringing the rainwater or desalinated seawater to the original volume, or by water from underground mineralized water source in for further electrolysis.

The proposed method is shown in Fig. 3, which shows a flow chart for the preparation of slightly alkaline water from a "cocktail" obtained in the manner described above. 


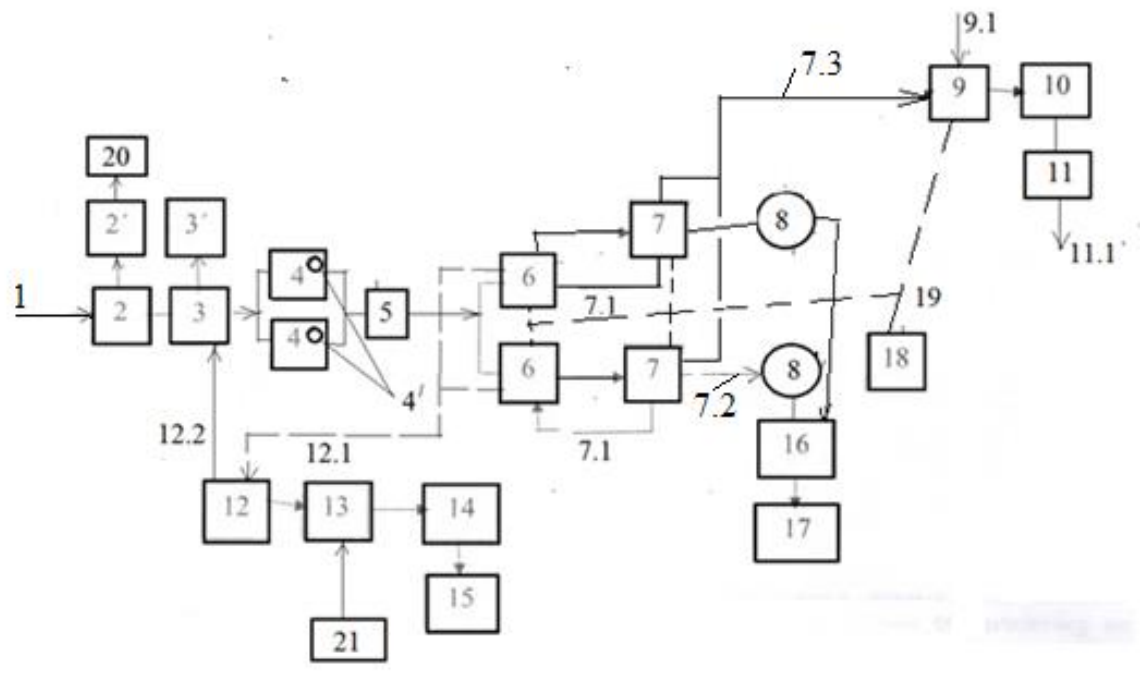

Fig. 3. The proposed method.

Notes:

1. The flow of domestic sewage;

2. Lattices.

2' Containers with garbage from lattices

3. Peskolovki.

3' Containers with sand

4. Cost-Mediators.

4. Pumps-dosers of the average hourly flow

5. Chamber for the distribution of wastewater flows

6. Sorption filters-denitrifiers.

7. Biotor plant - cultivator of nitrifying free-floating active sludge

7.1. Recirculation flow of nitrified water;

7.2. Regeneration water;

7.3. Purified nitrified water

8. Sludge of excess sludge

9. Bioreactor after-treatment;

9.1. Fresh water

10. UV or ozonator

11. Reservoir of "living" water

11.1. Baking water to consumers.

12. Sludge wet compact

12.1. Regeneration water;

12.2. Nadilovaya water.

13. Sewage sludge dewatering apparatus

14. Biocomposters

15. Fertilizer storage.

16. The capacity of excess sludge.

17. Growing pool for fish

18. Blowing

19. Air ducts

20. Worm shredder from containers $2^{\prime}$

21. Reagent farm.

\section{Results of the study}

The Southern Federal District of the Russian Federation is specific in that it is rich in rainfall and glaciers in mountainous areas. Residents of villages, settlements, remote from rivers with fresh water, have long since adapted to accumulate rainwater for personal and household needs, and in arid periods of the year they used accumulated rain or thawed water for drinking purposes. For hygienic needs, water from rivers, wells with increased salt content, was used, which was unsuitable for drinking and cooking. Insufficient intake of mineral salts, ions, and cations with drinking water was compensated by adding them to food [9]. 
In modern conditions, weakly alkaline water can be obtained by mixing in fresh water reservoirs accumulated during rains or desalinated from sources with increased salinity, with biologically purified domestic sewage water, brought to the quality of standards regulated for the breeding of valuable fish species, but this mixture must undergo treatment microalgae such as chlorella and spedesdemus to improve its taste and enrichment with oxygen, carbonates obtained by microalgae from the air due to absorbed They include compounds contained in the exhaust gases of road and air transport, combustion products of fuel during heating of dwellings [9].

A mixture of "dead" rain or desalinated salt water with biologically purified sewage enriched with nutrients (products of human life), in a certain ratio, as a rule, not more than 10: 1 , where 10 - the proportion of biologically purified water, and 1 - the proportion of natural water, which compensates for water losses due to evaporation and sewage sludge, makes it possible to obtain weakly alkaline water, which provides longevity of people and is suitable for watering green plantations, for example, in greenhouses [10].

According to modern forecasts, with the emergence of a global problem of excessive consumption of resources, including such vital as water and oxygen, Russian ecological abundance is becoming increasingly important both for Russia itself and for all mankind as a whole [10].

Russia is one of only three countries, which, according to experts, will not face a deficit of quality fresh water in the 21 st century. According to the reserves of water resources, the country takes the leading place in the world. Water resources are of particular importance for the development of the national economy and the maintenance of socio-economic programs in the regions of the country. The average annual renewable water resources of Russia make up $10 \%$ of the world river flow (second place in the world after Brazil) and are estimated at 4.3 thousand $\mathrm{km} 3$ per year. In general, the availability of water resources in the country is 30.2 thousand cubic meters. m per person per year.

Thus, the proposed method for obtaining weakly alkaline water suitable for domestic purposes can be used for water supply of the population in areas with a strained water regime, since it allows saving water resources by partially recycling (having passed a full cycle of deep biological sewage) and using the economical regime water use (collection of rainwater, collection of salt water, not previously used without preliminary treatment, previously not used in the national economy). Based on the forecast of experts from the WHO and the United Nations for the coming century to reduce the stocks of water suitable for life, the list of criteria for sustainable development and the ranking of cities should also include indicators of sewage recycling (or other methods of reducing water deficit).

\section{References}

1. N.I. Kulikov, Artificial cycles of water, air and food as a life-support system for a new generation (Lennard Publishing House, Moscow, 2016)

2. R.V. Krivonosov, Organizational and economic mechanism for regulating the sustainable development of the forest sector in the region (on the materials of the Krasnodar region), Abstract of the Ph.D. (Krasnodar, 2012)

3. E.P. Kovaleva, A.Ya. Lysenko, D.P. Nikitin, Urbanization and the problems of epidemiology (Medicine, Moscow, 1982)

4. A.V. Marukhno, V.V. Zhirma, T.A. Achmiz, Science yesterday, today, tomorrow: a collection of articles on the materials of IV International Scientific and Practical Conference (SibAK, Novosibirsk, 2013) 
5. On the state of sanitary and epidemiological welfare of the population in the Krasnodar region in 2016: State report (Office of Rospotrebnadzor Krasnodar region, Krasnodar, 2017)

6. N.I. Kulikov, A.N. Nozhevnikova, G.M. Zubov, Purification of municipal wastewater with repeated use of water and treated sediments: theory and practice (Logos, Moscow 2015)

7. M.G. Onoprienko, Water and life on the planet Earth: scientific-popul. essay (RIC FGBOU HPE SSU, Sochi, 2014)

8. N.I. Kulikov, Water supply: a manual (LLC "CSRNI", Novosibirsk, 2016)

9. N.I. Kulikov, L.N. Prikhodko, Engineering Bulletin of the Don 1 (2018) ivdon.ru/ru/magazine/archive/ n1y2018/4703

10. Rating of sustainable development of Russian cities (2012-2013), http://green-agency.ru 